\title{
Therapeutic Prospective of Stem Cells in Veterinary Practice
}

\author{
Suranji Wijekoon HI* \\ Department of Veterinary Clinical Sciences, Faculty of Veterinary Medicine and \\ Animal Sciences, University of Peradeniya, Sri Lanka
}

*Corresponding author: Suranji Wijekoon HM, Veterinary Teaching Hospital, Department of Veterinary Clinical Sciences, Faculty of Veterinary Medicine and Animal Science, University of Peradeniya, Peradeniya 20400, Sri Lanka, Tel: +94715960729; Email: suranjisk@gmail.com
Volume 4 Issue 2

Received Date: May 02, 2019

Published Date: May 14, 2019

DOI: $10.23880 /$ oajvsr-16000179

\section{Mini Review}

\section{Abstract}

Therapeutic application of stem cell in veterinary medicine continues to develop rapidly both experimentally and clinically. Identification and isolation of multi-potential capability of stem cells from different sources of animal tissues and testing their efficacy to use in regenerative medicine are the novel trend in tissue engineering. Several animal models are being using for preclinical evaluation of stem cell applications in human and animal in areas such as spinal cord injury, cartilage defects, ligament defect and myocardial infarction. Today, numerous veterinary diseases are being treating with the administration of stem cells. However, these applications have not been implemented well, to overcome the challenges faced by the clinicians. Further, with the limited data the therapeutic role of stem cells in regenerative medicine is not fully understood. This review will emphasize the application of stem cell therapy in veterinary medicine offering a safe and clinically effective tool for the clinician to assist treatment of the animal.

Keywords: Stem Cells; Pluripotent Mesenchymal Stem Cells; Stem Cell Therapy; Animal Health

\section{Sources of Stem Cells}

Stem cells have evoked considerable interest among the human and animal-owning public because of the promise that stem cell technology could deliver tissue regeneration for injuries for which natural repair mechanisms do not deliver functional recovery and current therapeutic strategies have minimal effectiveness. Different organs and tissues carry stem cells for the regeneration of tissue and organ systems. Pluripotent mesenchymal stem cells (MSCs) are able to differentiate into lineages of mesenchymal tissues such as cartilage, bone, fat, muscle, tendon and other cells of the mesenchymal lineage under appropriate stimuli [1-3].
Most of the studies have been focused on finding MSCs in different parts of the body for medical treatment. Canine bone marrow-derived mesenchymal stem cells offer a significant promise as a multipotent source for cell-based therapies [4,5]. However, most of the studies have been focused on finding MSCs in different parts of the body for regenerative medicine. The synovial membrane is the most specific mesenchymal tissue among joint structures. It carries resident MSCs, have the potential of multiple differentiation ability into chondrogenic, adipogenic and osteogenic lineage as verified by Alcian blue, Oil red 0 , and Alizarin red S positive stain, respectively based on previously described protocol [1-3]. Pluripotent embryonic stem cells derive from the fertilization of the egg, and they have ability to differentiate into any of the three germ layers (endoderm, 
mesoderm, or ectoderm); thus, they possess the potential to differentiate into any cell lineage and apply in clinical practice [6,7]. In cartilage tissue engineering, both adipose-derived stromal/stem cells and BMCs based cell therapies cite the merits [8]. Moreover, In vitro studies using rabbit peripheral blood cells (PBSCs) have shown that greater chondrogenic and adipogenic differentiation potential in in vitro assays by proving the carrying capacity of stem cells. Both BMSc and PBSCs were capable to produce similar chondrogenic results in an in vivo cartilage defect model, generating the cartilage rich in proteoglycans and collagen which closely resembled native cartilage [9]. Another novel source of stem cells for tissue engineering is the umbilical cord/ umbilical cord blood which carrying the ability of cartilage repair and regeneration in supplemented environment [10-12].

As illustrated in above facts, wide variety of tissue have been identified as ideal sources for stem cell population with different degree of invasiveness, cell yield, cell proliferation, and chondrogenic potential [13]. Easy of harvest and available cells number are the most critical factors to be concerned while selecting the best source for stem cell isolation.

\section{Stem Cells in Veterinary Regenerative Therapy}

Recent clinical studies unveiled intriguing stem cell therapeutic options including, spinal cord injury, enhance wound healing, bone, cartilage and cardiovascular repair $[14,15]$. Recently many researches are progressing in vitro expansion of stem cells for direct clinical application and most favorable stem cells sources are bone marrow and adipose tissue [16-19]. Application of MSCs is not limited in large animal practice thus recently reports spectacle the novel application in small animal practices.

\section{Cartilage Defects}

Selection of successful treatment for articular cartilage injury remains a major challenge for both orthopedic clinicians in human and animal practice as untreated condition ultimately end up in osteoarthritis and degenerative joint diseases. While practicing several treatment option for articular cartilage repair, cell based therapies have emerged as a novel aspect of means of treating focal cartilage injuries. A trend has being emerged in veterinary tissue engineering to use healthy chondrocytes harvested from a non-weight-bearing area of the joint and then transplanted back into cartilage lesions following in vitro isolation and culture expansion [20-25]. In order to overcome the technical difficulties associated with using autologous chondrocytes implantation MSCs aroused with the nature of easy isolation and laboratory based-expanding in sufficient amount of cells [20-24].

\section{Bone Repair}

Tissue engineering is a viable alternative to the highly invasive surgical repair of bone defect that has promising advantage in restoring both the structure and function of damaged bone. According to the recent findings, MSCs can undergo osteogenic differentiation and in vitro expanded stem cells can augment bone repair and regeneration $[3,26]$. Intriguingly, few studies have shown that nonunion fractures were cured by autologous transplantation of adipose and bone marrow derived MSCs in dogs and horses [27-29]. The recruitment, proliferation, migration, and accumulation of periosteal progenitor and bone marrow stromal cells precede and are concurrent with differentiation into osteoblasts and chondrocytes at the defect.

\section{Spinal Injury}

The spinal injuries are common in canine and feline that eventually leads to muscle atrophy with myelinated fiber tracts and loss of function due to limited regenerative capacity of locomotor activity. Transplantation of stem cells with ability to differentiate into neurons and other supporting cells might be promising therapeutic option for recovering from acute injuries [30].

\section{Tendon and Ligament Repair}

Tendon injuries are currently managed by conservative treatments which target the pain relief and surgical repair. Even after the repair, repeated ruptures, joint stiffness, and movement restriction are common problems arising with the inability of self-repair of tendon [31]. Recent studies confirm that changes of microenvironment after the injury initiate massive differentiation of stem cells in tendon and cause pathological ossification and failed tendon healing after injury [32]. To overcome the mechanical properties of healing tendency in tendons and ligaments, stem cell therapy comes as alternative treatment. Bone marrow derived MSCs along with collagen gel were applied to repair surgically induced patellar tendon defect in New Zealand White rabbits and achillies tendon repair in rabbit models [33,34]. The use of stem cells to repair tendon is particularly exciting and promising as stem cells have the potential to differentiate into tenocytes and promote tendon regeneration. Therapeutic application of 


\section{Open Access Journal of Veterinary Science \& Research}

adult stem cells and adipose derived MSCs in several clinical studies on race horse tendinopathies and orthopedics is well studied [35-37].

\section{Wound Repair}

Normal wound healing is a dynamic and complex multiple phase process with multidisciplinary interaction between growth factors, cytokines, chemokines, and various cells. Healing process is depends on care involves, control infection and debride the tissue while addressing ischemia and diabetes in certain patients. Nevertheless, the efficacy of the current treatment modalities is a limited success and incurs considerable costs. The approach of regenerative medicine has emerged as an alternative to provide additional therapeutic options to potentially improve wound healing and restore normal skin architecture [38-40]. Several animal models including, rabbits and sheep have been used to study the efficacy of wound healing after treatment of stem cells $[41,42]$.

\section{Conclusion}

All the fact summarize in this review emphasis that stem cells are undoubtedly most promising for tissue engineering thereby provides an effective and flexible option for veterinarians to restore function and animal health in order to upgrade the veterinary field in both companion and farm animal. Through the optimization of stem cell-based therapies, veterinarians might be able to provide advanced service to enhance the tissue engineering in low cost, safe and effective manner. However, stem cell-based therapeutics requires extensive research based studies to standardize the treatment protocols, routes and doses as well as guidelines and regulations. Moreover, stem cell field in veterinary medicine continues to evolve rapidly both experimentally and clinically with the efforts of vet-scientists in development and implementation of these innovative strategies to improve farm and pet animal health.

\section{References}

1. Branco DSE, Casado PL, Neto VM, Leite DME, Aguiar DP (2014) Synovial fluid and synovial membrane mesenchymal stem cells: latest discoveries and therapeutic perspectives 5(5): 112.

2. De Bari C, Dell'accio F, Tylzanowski P, Luyten FP (2001) Multipotent mesenchymal stem cells from adult human synovial membrane. Arthritis Rheum 44(8): 1928-1942.
3. Wijekoon HMS, Toyota K, Kim S, Fang J, Bwalya EC, et al. (2017) Differentiation potential of synoviocytes derived from joints with cranial cruciate ligament rupture and medial patella luxation in dogs. Research in Veterinary Science 114: 370-377.

4. Kisiel H, McDuffee L, Masaoud E, Bailey TR, Esparza Gonzalez BP, et al. (2012) Isolation, characterization, and in vitro proliferation of canine mesenchymal stem cells derived from bone marrow, adipose tissue, muscle, and periosteum. Am J Vet Res 73(8): 13051317.

5. Csaki C, Matis U, Mobasheri A, Ye H, Shakibaei M (2007) Chondrogenesis, osteogenesis and adipogenesis of canine mesenchymal stem cells: a biochemical, morphological and ultrastructural study. Histochem Cell Biol 128(6): 507-520.

6. Caplan AI (2017) Mesenchymal stem cells: time to change the name! Stem Cells Translational Medicine 6(6): 1445-1451.

7. Dennis JE, Carbillet JP, Caplan AI, Charbord P (2002) The STRO-1+ marrow cell population is multipotential. Cells Tissues Organs 170(2-3): 73-82.

8. Owen M, Friedenstein AJ (1988) Stromal stem cells: marrow-derived osteogenic precursors. Ciba Foundation Symposium 136: 42-60.

9. Fu WL, Zhou CY, Yu JKA (2014) A new source of mesenchymal stem cells for articular cartilage repair: MSCs derived from mobilized peripheral blood share similar biological characteristics in vitro and chondrogenesis in vivo as MSCs from bone marrow in a rabbit model. The American Journal of Sports Medicine 42(3): 592-601.

10. Ha CW, Park YB, Chung JY, Park YG (2015) Cartilage repair using composites of human umbilical cord blood-derived mesenchymal stem cells and hyaluronic acid hydrogel in a minipig model. Stem Cells Translational Medicine 4(9): 1044-1051.

11. Li X, Duan L, Liang Y, Zhu W, Xiong J, et al. (2016) Human umbilical cord blood-derived mesenchymal stem cells contribute to chondrogenesis in coculture with chondrocytes. BioMed Research International 2016: 3827057-3827059.

12. Park YB, Ha CW, Kim JA, Han WJ, Rhim JH, et al. (2017) Single-stage cell-based cartilage repair in a rabbit model: cell tracking and in vivo 


\section{Open Access Journal of Veterinary Science \& Research}

chondrogenesis of human umbilical cord bloodderived mesenchymal stem cells and hyaluronic acid hydrogel composite. Osteoarthritis and Cartilage 25(4): 570-580.

13. James NF, Irene $\mathrm{T}$, Bertocco $\mathrm{T}$, Guiseppe MP, Laura M (2017) The application of stem cells from different tissue to cartilage repair. Stem cells Int 2017: 2761678 .

14. Carvalho AM, Alves ALG, Oliveira PGG, Alvarez LEC, Amorim RL, et al. (2011) Use of Adipose TissueDerived Mesenchymal Stem Cells for Experimental Tendinitis Therapy in Equines. J Equine Vet Sci 31(1): 26-34.

15. Lee KB, Choi J, Cho SB, Chung JY, Moon ES, et al. (2011) Topical embryonic stem cells enhance wound healing in diabetic rats. J Orthop Res 29(10): 15541562.

16. Broxmeyer HE (2005) Biology of cord blood cells and future prospects for enhanced clinical benefit. Cytotherapy 7(3): 209-218.

17. Bwalya EC, Kim S, Fang J, Wijekoon HMS, Hosoya K, et al. (2017) Effects of pentosan polysulfate and polysulfated glycosaminoglycan on chondrogenesis of canine bone marrow-derived mesenchymal stem cells in alginate and micromass culture. Journal of Veterinary Medical Science 79(7): 1182-1190.

18. Wijekoon HMS, Bwalya EC, Kim S, Fang J, Hosoya K, et al. (2018) Inhibitory effects of pentosan polysulfate on formation and function of osteoclasts derived from canine bone marrow. Journal of BMC Veterinary Research 14(1): 152.

19. Fortier LA, Potter HG, Rickey EJ, Schnabel LV, Foo LF, et al. (2010) Concentrated bone marrow aspirate improves full-thickness cartilage repair compared with microfracture in the equine model. J Bone Joint Surg Am 92(10): 1927-1937.

20. Krych AJ, Gobbi A, Lattermann C, Nakamura N (2016) Articular cartilage solutions for the knee: present challenges and future direction. JISAKOS 1(2):1-12.

21. Bernhard JC, Vunjak-Novakovic G (2016) Should we use cells, biomaterials, or tissue engineering for cartilage regeneration? Stem Cell Res Ther 7: 56.
22. Madeira C, Santhagunam A, Salgueiro JB, Cabral JM (2015) Advanced cell therapies for articular cartilage regeneration. Trends Biotechnol 33(1): 35-42.

23. Hunziker EB, Lippuner K, Keel MJB, Shintani N (2015) An educational review of cartilage repair: precepts \& practice-myths \& misconceptions-progress \& prospects. Osteoarthritis Cartilage 23(3): 334-350.

24. Myers KR, Sgaglione NA, Grande DA (2013) Trends in biological joint resurfacing. Bone Joint Res 2(9): 193199.

25. Thiede RM, Lu Y, Markel MD (2012) A review of the treatment methods for cartilage defects. Vet Comp Orthop Traumatol 25(4): 263-272.

26. Kraus KH, Kirker C (2006) Mesenchymal stem cell and bone regeneration. Vet surg 35: 232-242.

27. Lee HB, Chung YS, Heo SY, Kim NS (2009) Augmentation of bone healing of nonunion fracture using stem cell based tissue engineering in a dog: a case report. Veterinarni Medicina 54(4): 198-203.

28. Arinzeh TL, Peter SJ, Archambault MP, Bos C, Gordon S, et al. (2003) Allogeneic Mesenchymal Stem Cells Regenerate Bone in a Critical-Sized Canine Segmental Defect. J Bone \& Joint Surg 85(10): 1927-1935.

29. Torricelli P, Fini M, Filardo G, Tschon M, Pischedda M, et al. (2011) Regenerative medicine for the treatment of musculoskeletal overuse injuries in competition horses. Int Orthop 35(10): 1569-1576.

30. Gade NE, Pratheeesh MD, Nath A, Dubey PK, Amarpal Sharma GT (2012) Therapeutic potential of stem cells in veterinary practice. Vet World 5(8): 499-507.

31. Liu PPY (2015) Stem cell technology for tendon regeneration: current status, challenges, and future research directions. Stem Cells Cloning 8: 163-174.

32. Rui YF, Lui PP, Chan LS, Chan KM, Fu SC, et al. (2011) Does erroneous differentiation of tendon-derived stem cells contribute to the pathogenesis of calcifying tendinopathy? Chin Med J 124(4): 606-610.

33. Awad H, Butler D, Boivin G, Smith FN, Malaviya P, et al. (1999) Autologous mesenchymal stem cell Transplantation of cardiac-committed mediated repair of tendon. Tissue Eng 5(3): 267-277. 


\section{Open Access Journal of Veterinary Science \& Research}

34. Butler D, Awad H (1999) Perspectives on cell and collagen composites for tendon repair. Clin Orthop Rel Res 367: S324-S332.

35. Koch TG, Berg LC, Betts DH (2009) Current and future regenerative medicine - principles, concepts, and therapeutic use of stem cell therapy and tissue engineering in equine medicine. Can Vet J 50(2): 155165.

36. Frisbie DD, Smith RK (2010) Clinical update on the use of mesenchymal stem cells in equine orthopaedics. Equine Vet J 42(1): 86-89.

37. Turner NJ, Badylak SF (2015) The use of biologic scaffolds in the treatment of chronic nonhealing wounds. Adv Wound Care 4(8): 490-500.

38. Dickinson LE, Gerecht S (2016) Engineered biopolymeric scaffolds for chronic wound healing. Front Physiol 7: 341.
39. Duscher D, Barrera J, Wong VW, Maan ZN, Whittam AJ, et al. (2016) Stem cells in wound healing: the future of regenerative medicine? A mini-review. Gerontology 62(2): 216-225.

40. Mackenzie TC, Flake AW (2001) Human mesenchymal stem cells persist, demonstrate site specific multipotential differentiation, and are present in sites of wound healing and tissue regeneration after transplantation into fetal sheep. Blood Cells Mol \& Dis 27(3): 601-604.

41. Stoff NS, Moore ST, Numnum M, Espinosa-de losMonteros A, Richter DF, et al. (2009) Promotion of incisional wound repair by human mesenchymal stem cell transplantation. Exp Dermatol 18(4): 362369. 